\title{
CATADORAS DE CARANGUEJ O E SABERES TRADICIONAIS NA CONSERVAÇÃO DE MANGUEZAIS DA AMAZÔNIA BRASILEIRA
}

\author{
DENISE MACHADO \\ Universidade Federal do Pará
}

\begin{abstract}
Resumo: A catação de caranguejo (Uc ides cordatus) desenvolvida por mulheres ca boc las em áreas do litoral norte da região a mazônica, precisamente no nordeste paraense, possibilita a análise da problemática ambiental e relações de gênero a partir de uma abordagem antropológica sobre uma parcela da população tradicional amazônica. Quanto à questão ambiental, é tratada em termos de conservação, manejo e conhecimento de recursos ambientais. Evidenciou-se que a pesca desenvolvida nas áreas de manguezais na vila de Gua rajubal é feita artesanalmente e direcionada à captura e beneficiamento do caranguejo, com o trabalho decisivo das mulheres a partir da maior demanda nos centros urbanos próximos. 0 trabalho dasc atadoras Ihes possibilita ma nifesta rem-se em relaçã o a os problemas a mbienta is, ainda que no contexto local.
\end{abstract}

Palavras-chave: catadoras; pesca, ec ofeminismo, Guarajubal.

\section{Introdução}

A questão ambiental tem sido uma preocupação constante nos dias atuais, pois problemas de poluição, degradação a mbiental e pobreza permeiam as relações socia is em nível regional e mundial. A preocupação simultânea envolvendo o ambiente e as problemáticas de gênero, de trabalho e de educação vem sendo uma decorrência da complexida de dessa questão. A mulheré um ind ivíduo de extrema importância na questão a mbiental por estar extremamente ligada a manejo de recursos vitais para o grupo doméstico do qual faz parte. ${ }^{1}$ Esses recursos a mbienta is (hídricos, a gríc olas e silvíc olas) são de uma abrangência ímpare dizem respeito tanto àsplantas medic ina ise à sutiliza das na a limentação quanto à forma como são controladas em sua utilização pela mulher. 
No entender de Davidson, ${ }^{2}$ em países em desenvolvimento, é difícil definir onde o a mbiente começa e termina para a mulher, pois todas as atividades de desenvolvimento de algum modo afetam seu espaço. As mulheres em geral, mas especialmente aquelas das so c ieda des com ca rac ceństic a s tra dic iona is, desenvolvem múltipla s a tivida des dura nte o dia e no começo da noite.

Conforme verificado em Guarajubal, ${ }^{3}$ e também em outras populações amazônicas ${ }^{4}$ as mulheres se envolvem em uma série de outras tarefas que não aquelas voltadas, necessariamente, à produção de renda. Assim, cabem a elas as atividades ligadas a os cuidados com a saúde dos membros da família, cuidado com a cria ção de a nima is em seus quintais, com a roça, transporte de água, lenha e de produtos dos roçados, dentre outras. Muitos desses fazeres se encontram intimamente relacionados ao a mbiente em que vivem, o que é mediatizado por suas próprias culturas e sociedades.

Os procedimentos metodológicos deste estudo tiveram como referência a perspec tiva de produção a ntropológica, ${ }^{5}$ notada mente no âmbito dos estudos de Ecologia Humana e de gênero. O levantamento da bibliografia e da documentação pertinente foi feito nas cidades de Belém e Marapanim. No campo a observação participante ba seouse na utilização de conversas informais, entrevistas não dirigidas, registros fotog rá fic os e questionários.

As variáveis pesquisadas dizem respeito aos aspectos históricos, econômicos e cultura is de Gua rajubal. Foram privilegiados os aspectos liga dos a o manejo das áreas de mangueza is e os impactos da ativida de econômic a de produção e comercialização de massa de caranguejo nesse ecossistema. A coleta de dados sobre a história e a literatura oral referentes a os ec ossistemas presentes na regiã o foi desenvolvida a partir de perspectiva que privilegia a caracteriza ção segundo categorias loca is. Dessa maneira, a coleta de dados se espelhou na perspectiva da etnoecologia, bem como em ecofolque ${ }^{6}$ e história oral por privilegiarem categorias e formas de classificação loca is. Essas abordagens permitem que se dê importância a dimensões que poderiam ser esquecidas devido a os preconceitos cultura is do pesquisador. Além disso, tais técnicas permitem que se vá descobrindo gradativamente as estruturas lógicas referentes à percepção sobre o a mbiente físico e social.

\section{Mulheres e atividades de catação}

Apesar de as mulheres desenvolverem múltiplas tarefas, o trabalho feminino é invisibiliza do e considerado de menor relevância para a sociedade a que pertencem. No

\footnotetext{
2 J oan DAVIDSON, 1993.

${ }^{3}$ A vila de Guarajubal faz parte, política e administrativamente, do município de Marapanim. Sua origem está inserida no contexto de expansão de ca tequiza ção de indíg enas porordens religiosa s jesuítas, presentes na região desde o século XVII (Antônio CONCEIÇÃO, 1995).

${ }^{4}$ Ligia SIMONIAN, 2000.

${ }^{5}$ Este artigo foi produzido a partir da pesquisa realizada no Mestrado em Antropologia Social/UFPA, no período 1998-2000. As pessoas da vila pesquisada sabiam das intenções da investigação e aceitaram contribuir com o estudo. Do mesmo modo, permitiram serem identificadas no texto por mim elaborado e não demonstra ram resistência quanto a isso. Ao longo da pesquisa fora $m$ a presentadas versões parcia is do texto aos informantes. Como a pesquisa foi realizada em três etapas (1998: survey; 1999: ida mensal a campo - finais de semana e feriados prolongados; 2000: permanência em campo - dois meses), houve várias oportunida des de diálogo com essas pessoas. Isso deu segurança a o que estava para ser produzido e garantiu a "autoridade etnográfica" na a presentação do texto final.

${ }^{6}$ Estudo integral do correlacionamento do comportamento humano com fatores ambientais. Permite explic ações sobre todos os fa tores que constituem os complexos componentes cultura is do folc lore (Antônio SILVA, 1991).
} 
caso de seruma mulhercabocla é comum que haja ma is um motivo para sua depreciação, pois essa população tra dicional a mazônica tem sido discriminada por diferentes espaços e segmentos sociais. Quando essa mulher cabocla é identificada como pescadora a situação se toma mais complexa, na medida em que o trabalho na pesca é pouco considerado pelo poder público e pela própria academia, o que por certo acarreta 0 esquecimento desse setor em relação a outras atividades desenvolvidas por essa população tradicional.

Em meio a essa situação de pouca visibilidade dos caboclos há, ainda, a desconsideração do trabalho feminino em áreas de mangueza is. Nessas áreas as mulheres coletam moluscos e crustáceos, mas esse trabalho é pouco valorizado entre os próprios pescadores porque não está ligado diretamente à captura de peixe em alto-mar.

Em Guarajubal essa visão é decorrente da própria formação de pescadores que privilegia a aprendizagem do saber ligado à pesca apenas aos homens, cabendo à mulher outras atividades produtivas. Nessa vila a identidade masculina é construída a partir do aprendizado ligado à pesca, e quando um homem não sabe pescar ele tem dificuldades em servaloriza do e considerado importante, mesmo que desenvolva outras tarefas. Quando uma mulherpesca, ela o fazdesenvolvendo a chamada pesca pequena, ou pesca da beira.

O caranguejo é relevante economicamente para a vila de Guarajubal devido à produção e comercialização de sua massa, garantindo obtenção de renda para os moradores, principalmente para um grande número de mulheres dessa localidade. Entretanto, tal trabalho não é reconhecido como relevante pelos habitantes locais que vêem na pesca do peixe uma atividade mais importante. Todavia, a pesca quando é tra ta da em seu sentid o a mplo permite a visua liza ção dos traba lhos de mulherese cria nças na captura de espécies aquáticas que não se restringem aos peixes.

o conhecimento tradicional que as mulheres possuem sobre seu ambiente é essencial para preservação das espécies, principalmente em países cuja economia depende de recursos biológicos. Segundo Woortmann, ${ }^{7}$ à mulher cabe a socialização atra vés da a prendizagem de saberes liga dos a o cultivo da terra e a os cuidados da casa. Mesmo assim, e em especial quando se trata da Amazônia, muito pouco tem sido feito pelo Estado, agências financiadoras, organizações não-govemamenta is (ONGs) e pelas próprias populações tra dic iona is, no sentido de utilizar esses saberes no desenvolvimento local e sustentá vel. ${ }^{8}$ Nessa perspectiva, a relação entre mulheres, gênero, meio ambiente e desenvolvimento é não só permanente como muito estreita.

A comercialização da came de caranguejo (Ucidescordatus) na vila de Gua rajubal tem causa do impactos a mbienta is que poderão a carretar a degradação completa dos mangueza is dessa região. Localizada a 117 km da capital do estado do Pará, no Norte do Brasil, Guarajubal tem como principal atividade produtiva o processo de catação desenvolvido pelas mulheres.

A partir do levantamento feito em campo, sabe-se que a catação de caranguejo foi introduzida no local há aproximadamente 17 anos, a tra vés de um senhor conhecido como "Paulo Sarará". E, pelo que foi relatado por uma catadora de nome Ana Lúcia, 39 anos, as pessoas de Guarajubal sempre cataram caranguejo, todavia somente para o próprio consumo. Essa situação foi alterada com a vinda do Sr. Paulo, quando a ca tação passou a ser feita com fins comerciais.

\footnotetext{
7 Ellen WOORTMANN, 1992.

${ }^{8}$ SIMONIAN, 1998.
} 
As mulheres catadoras de caranguejo não têm o reconhecimento da importância de seu trabalho, nem tampouco são reconhecidos pelo poder público os seus saberes tradicionais na conservação de manguezais. Conseqüentemente, as ações govemamenta is ligadas ao desenvolvimento da região norte do esta do do Pará ca recem de participação dessas mulheres na formulação de uma agenda que inclua os seus saberes sobre manejo menos impactante.

\section{Mulheres caboclas e a conservação de mangueza is da Amazônia brasileira}

A produção de massa de caranguejo exige conhecimento da técnica de catação e envolve conhecimentos tradicionais sobre o caranguejo, o mangal, o rio, as marés. Portanto, é importante conhecer todo o ecossistema ligado de forma direta ou indireta à vida desse crustáceo. Nessa a tividade estão inter-relacionados os saberes loca is sobre o ambiente e os valores e crenças da população humana que ora habita na região de Guarajubal.

Há diversos tipos de caranguejo e os habitantes de Guarajubal os classificam em seis grupos: Caranguejo-Uçá, Ma nic ujá, Ma raquanim, Aratu, Sarará Pa trona e Guaia mun. O grupo composto pelo tipo de caranguejo Uçá (Ucides cordatus) é mais comum e é por eles tid o como normal; o segundo grupo é o do caranguejo Manic ujá e foge um pouco do padrão, pois, a o contrário do Uçá, possui as duas patas com tamanho semelhante.

A fêmea do caranguejo não é tirada do mangal e, quando isso eventualmente ocorre, é motivo de la menta ção pelo tira dor. A captura da fêmea (denominada loca lmente como condessa) é proibida por lei e também não é feita pelos tiradores porque reconhecem que para cada fêmea ovada haverá centenas, ou até milhares de caranguejo no futuro no mangal. Segundo rela to do tirador Chavoca, "Do verão passa do para esse verão a diminuição é de $100 \%$. Antes eu tirava 60 a 70 caranguejos numa manhã, hoje tiro 35 . Ontem mesmo tirei só $29 "$. Tal relato demonstra a preocupação em manter o equilíbrio das áreas de manguezais.

A produç ão da massa propriamente dita tem iníc io com o cozimento do caranguejo em pequenas fogueiras a lenha. Após o cozimento a came do caranguejo é retirada a partir de leves batidas com pequenos pedaços de madeira sobre o animal, cuja casca será separada da came. É necessá ria certa habilidade e destreza para que a casca não seja triturada e misturada à came ou que esta não seja esmagada com batidas, o que causaria uma perda na qualidade do produto. Posteriormente, a massa é armazenada em sacos plástic os para venda.

O controle e destino no orçamento doméstico do dinheiro recebido pela massa de caranguejo produzida é estabelecido pelas catadoras, para compra principalmente de comida: pão, came e frango. Na medida do possível, o dinheiro é direcionado para compra de material escolarde seus filhos ou roupas. Portanto, prioritaria mente para atender às nec essida des da s fa mílias.

A cadeia de produção e comercialização da massa de caranguejo presente em Guarajubal mostra, segundo Sena, ${ }^{9}$ o embrião da estruturação de uma integração da vila com a economia capitalista, a inda que rudimentar, pois os moradores são os proprietários dos meios de produção com os qua is trabalham e detêm o conhecimento do saber relacionado a todo o processo produtivo.

${ }^{9}$ Ana Laura SENA, 1999. 
A produção de massa de caranguejo, bem como sua inserção a o mercado, conta com uma relativa especialização de tarefas realizadas segundo idade, sexo e estado civil das pessoas ligadas a esse tipo de trabalho. A atividade de catação é fundamental no beneficiamento da came de caranguejo, ga rantind o a comercializa ção e seu consumo nos municípios de Castanhal e Belém - capital do estado do Pará.

No que tange à utilização de áreas de manguezais, as mulheres caboclas de Gua rajubal considera m que o sob reuso dos recursos dos mangueza is tra rá o esg otamento dos mesmos. Motta considera que uma dascausas desse sobreuso de recursos natura is é a situação de empobrecimento, pois no seu entendimento "[...] p opulação empobrecida pode ser levada ao sobreuso destes recursos natura is e do a mbiente em geral, minando as próprias bases para um desenvolvimento sustentável a longo prazo".10 É possível que em Guarajubal a situação de pobreza se agrave e venha a se tomar um dos fatores relacionados à degradação a mbiental.

É consenso entre as catadoras de caranguejo de Guarajubal que o aumento do número de caranguejos tira dos do mangue é a principal causa da diminuição do tamanho e número populacional desse crustáceo na região de Marapanim. Embora haja reconhecimento de que a intensidade crescente da coleta de caranguejo tra rá impactos a suas vidas, essas mulheres convivem com a reduzida consideração de seu trabalho e de seus saberes tra dic iona is sobre as a tividades ligadas às dinâmic as dos mangueza is.

\section{Notas conclusivas}

O consumo de crustáceos, e de outros componentes da fauna de manguezais, faz parte da dieta alimentar dos habitantes de regiões litorâneas e de manguezais desde tempos remotos. O caranguejo destaca-se principalmente como fonte de alimento, compondo a culinária de habitantes de vilas e cidades próximas ou distantes da região litorânea do Pará.

$\mathrm{Na}$ vila de Guarajubal e em outras com características tradiciona is caboclas da região a ma zônica, homens e mulheres são explorados diante das crescentes demandas de consumo, como é o caso da procura pela massa de caranguejo. Essa demanda c rescente motiva as pessoas de Gua rajubal a capturar um número cada vez ma ior desse crustáceo, a carretando com isso a lterações a mbienta is irreversíveis num futuro próximo. Mesmo sabedores dessa situação, o poder público não age efetivamente diante das reivindicações de tiradores e catadoras.

A degradação ambiental é uma ameaça constante em Guarajubal, pois, apesar de os moradores se preocuparem em tirar apenas o caranguejo-macho do mangal, deixando a fêmea (condessa) e os caranguejos menores para procriação e crescimento, essa pode ser uma atitude a ser extinta num futuro próximo. Os impactos da produção de massa de caranguejo, a tra vés do beneficiamento da came desse crustáceo, tomaramse intensos e negativos, pois, quando a população local passou a ser motivada por demandas de mercado, a extração passou a tenderpara a insustentabilidade.

Porém, catadoras e tiradores de Guarajubal reconhecem que a captura desse crustáceo ainda em tamanho impróprio ao consumo humano manifesta-se ainda de forma incipiente, e com a implantação do período de defeso vislumbra-se o impedimento do sobreuso dos recursos dos manguezais, o que poderá viabilizar em Marapanim, e na região litoral paraense, a sustentabilidade dessa atividade.

\footnotetext{
${ }^{10}$ MOTTA, 1999, p. 37.
} 
Por fim, a problemática envolvendo gênero e meio ambiente se revela como da maior importância, embora ainda requeira maiores pesquisas e políticas públicas específicas. Nessa direção, no que diz respeito ao reconhecimento da participação das mulheres na conservação de áreas de manguezais, há todo um campo a ser explorado e trabalhado, tanto na Amazônia como em outras áreas.

\section{Referências bibliográficas}

CONCEIÇÃO, Antônio Azevedo. Marapanim: reconstituição histório-cultural, mística e chistosa. Belém: Grafinorte, 1995.

DAVIDSON, J oan. "Women's Rela tionship with the Enviroment." In: WEINSTEIN, Ra chel, HEDLEY, Rachel, and DAVIDSON, J oan (eds). Women and the Environment. Oxford: Oxfam, 1993. p. 9-12.

MOTTA, Ja ir Pereira. As áreas agríc olas do município de Maracanã: um estudo sobre as condições ambientais. 1999. Trabalho de Conclusão de Curso (Ciências Socia is), Universidade Federal do Pará, Castanhal, PA.

SENA, Ana Laura. dos Santos. Relatório de viagem de campo ao vilarejo de Guarajubal/ Pa rá. Belém: UFPA/NAEA, 1999. Digita do.

SHIVA, Vandana. "Women's Indigenous Knowledge and Biodiversity." In: MIES, Maria, and SHIVA, Vandana (eds.). Eco-feminism. Halifax, Nova Scotia: Fermwood Public ations, 1993. p. 164-173.

SILVA, Antônio Borda lo da. "Introdução a o estudo do folc lore a mazônic o". In: NASC IM ENTO, Brá ulio (Org). Estudos de folclore em homenagem a Manuel Diegues Júnior. Mac eió: Instituto Amon de Mello, 1991. p. 21-28. (Série Antropologia e Folclore).

SIMONIAN, Ligia Terezinha Lopes. Mujer y desarrollo en la Amazonia brasileña. In: J O RNADAS AMAZO NIC AS, 7., 1998, Puyo, Equador. Analles... Puyo, Equa dor, 1998.

. Mulheres do rio Aripuanã (AM): memórias, situação atual e esperanças quanto ao futuro. Manaus: SECULT-AM, 2000. Mimeo.

WO O RTM ANN, Ellen F. "Da complementaridade à dependência: espaço, tempo e gênero em 'comunid ades pesqueiras' do Nordeste". Revista Brasileira de Ciências Sociais, n. 18, p. 41-60, 1992.

\section{Crab Pickers and Traditional Knowledge in the Conservation of Brazilian Amazonian Mangroves}

Abstract: The crab (Ucides cordatus) picking, done by cabocla women in Northeast Pará of the North Coastal Amazon Region, permits the ana lysis of the environmental question and of gender relations from an anthropological a pproach on a spec ific Amazonian traditional population. The environmental question is dealt with in terms of conservation, hand ling and knowledge about environmental resources. Evidence shows that crab picking is an artisan activity developed in mangrove swamp areas near the town of Guarajubal in which catching and doing product betterment of the crab are women's work, stimulated by the growing demand from nea rby urban centers. The work of the catadoras (pic kers) allows them to manifest their opinions in relation to the environmental problems, albeit in the local context.

Key words: Catadoras; Fish; Ec ofeminism; Guarajubal. 